\title{
Contribuições das atividades experimentais no processo de aprendizagem de soluções
}

\section{químicas}

\author{
Contributions of experimental activities in the process of learning chemical solutions \\ Contribuciones de las actividades experimentales en el proceso de aprendizaje de soluciones \\ químicas
}

Recebido: 24/03/2021 | Revisado: 30/03/2021 | Aceito: 09/04/2021 | Publicado: 18/04/2021

Joselia Cristina Siqueira da Silva

ORCID: https://orcid.org/0000-0003-2448-9886 Universidade Federal do Paraná, Brasil

E-mail: jcristinaquimica@gmail.com

Gilmene Bianco

ORCID: https://orcid.org/0000-0002-2654-5370

Universidade Federal do Espírito Santo, Brasil

E-mail: gilmeneb@yahoo.com.br

Dieison Prestes da Silveira

ORCID: https://orcid.org/0000-0002-8446-4157 Universidade Federal do Paraná, Brasil

E-mail: dieisonprestes@gmail.com

Rodrigo Da Vitória Gomes

ORCID: https://orcid.org/0000-0002-7171-695X Universidade Federal do Paraná, Brasil

E-mail: rodrigodavitoriagomes@gmail.com

Deivid Jonas Silva da Veiga

ORCID: https://orcid.org/0000-0002-1625-0560

Universidade de Cruz Alta, Brasil

E-mail: deividveiga96@gmail.com

Lielle Serafim

ORCID: https://orcid.org/0000-0003-2737-5729

Universidade Federal do Espírito Santo, Brasil

E-mail: lielle.serafim@gmail.com

\begin{abstract}
Resumo
A Química é uma ciência natural, na qual, o conhecimento é construído a partir de fatos. As atividades experimentais permitem ao educando uma compreensão de como a Química se constrói e se desenvolve. Partindo desse pressuposto, buscou-se investigar a influência e contribuições das atividades experimentais no processo de aprendizagem de conceitos relacionados ao estudo das Soluções Químicas. A pesquisa contemplou 35 alunos matriculados na $2^{\mathrm{a}}$ série do Ensino Médio de uma escola pública estadual de Colatina-ES no ano de 2019, apresentando metodologia com abordagem qualitativa e experimental. Os dados foram analisados por meio do Método de Análise Observacional, permitindo-nos concluir que a utilização da experimentação no processo de ensino pode gerar incentivo à curiosidade e a pesquisa, potencializando os saberes dos educandos.
\end{abstract}

Palavras-chave: Atividade experimental; Estudo de soluções; Aprendizagem significativa.

\begin{abstract}
Chemistry is a natural science, in which, knowledge is built from facts. Experimental activities allow the student to understand how Chemistry is constructed and developed. Based on this assumption, we sought to investigate the influence and contributions of experimental activities in the process of learning of concepts related to the study of Chemical Solutions. The research included 35 students enrolled in the 2nd grade of high school at a state public school in Colatina-ES in 2019, presenting a methodology with a qualitative and experimental approach. The data were analyzed using the Observational Analysis Method, allowing us to conclude that the use of experimentation in the teaching process can generate incentives to curiosity and research, enhancing the students knowledge.
\end{abstract}

Keywords: Experimental activity; Solutions study; Meaningful learning.

\section{Resumen}

La química es una ciencia natural en la que el conocimiento se construye a partir de hechos. Las actividades experimentales permiten al alumno comprender cómo se construye y desarrolla la Química. Con base en este supuesto, se buscó investigar la influencia y las contribuciones de las actividades experimentales en el proceso de aprendizaje de conceptos relacionados con el estudio de Soluciones Químicas. La investigación incluyó a 35 
estudiantes matriculados en el $2^{\circ}$ grado de secundaria en una escuela pública estatal en Colatina-ES en 2019 , presentando una metodología con enfoque cualitativo y experimental. Los datos fueron analizados utilizando el Método de Análisis Observacional, lo que nos permitió concluir que el uso de la experimentación en el proceso de enseñanza puede generar un incentivo a la curiosidad y la investigación, potenciando el conocimiento de los estudiantes.

Palabras clave: Actividad experimental; Estudio de soluciones; Aprendizaje significativo.

\section{Introdução}

Com o desenvolvimento da educação, tornou- se evidente a necessidade de desenvolver no educando, a capacidade de interagir criticamente com as pessoas em seu meio. A ciência química está ligada diretamente ao cotidiano de um aluno. É necessário formar alunos aptos para sobreviver e atuar em uma sociedade de maneira responsável e comprometida ao mundo tecnológico científico, ressaltando e aflorando a sua capacidade de investigação, produção e desenvolvimento científico, interferindo assim diretamente no cotidiano do indivíduo.

O educando sente dificuldade de associar o conteúdo estudado em sala, com o seu cotidiano, tornando- o assim desinteressado por essa disciplina. Em alguns casos, há também certo despreparo por parte do professor, em atuar de forma interdisciplinar, relacionando essa ciência com a realidade dos alunos.

É ensinado ciência de forma abstrata, no qual não é incentivada a alfabetização científica, menos ainda, alunos que tenham pensamentos críticos, que sejam capazes de participar de forma relativa a uma sociedade pensadora e científica (Guimarães, 2009).

Há décadas estamos estagnados a hegemonia do modelo tradicional de ensino. Fragmentado e centrado no papel do professor transmissor de conhecimento. As aulas são essencialmente teóricas, cujo o aluno deve assimilar os conhecimentos que lhe são repassados seguindo uma sequência linear de conteúdo. Por isso não é exagero supor que muitas dificuldades de aprendizagem relacionadas ao ensino de química são decorrentes da inadequação das práticas pedagógicas (Guimarães, 2009).

Nesse modelo de ensino o aluno nada mais é que um agente passivo, que apenas ouve o que o professor fala. O aluno não expõe, não questiona e não interage, o que o coloca na posição de mero ouvinte. Muitas vezes, os conhecimentos prévios do educando não são considerados como fundamentais, e, desta maneira, dificilmente a aprendizagem será significativa (Guimarães, 2009).

Uma maneira de desenvolver e ampliar o processo de aprendizagem é a partir da contextualização. A contextualização não se limita apenas a exemplos de conteúdos específicos, mas de um exercício de docência mais amplo, no qual se propõem situações reais que estimulem o desenvolvimento do conhecimento com significado e senso crítico. No caso da disciplina de Química, essa orientação é de fundamental importância, pois seus conceitos estão presentes em muitos aspectos do cotidiano (Fiorucci, Soares \& Cavalheiro, 2002).

Sobre a contextualização do ensino, Wartha e Faljoni-Alário (2005, p. 43) acrescentam que "significa incorporar vivências concretas e diversificadas e também incorporar o aprendizado em novas vivências".

Uma das alternativas para facilitar o desenvolvimento crítico dos discentes e contextualizar os conteúdos propostos durante o processo de ensino e a realidade do educando é a utilização de atividades experimentais. A experimentação no ensino de química tem sua importância justificada quando se considera sua função pedagógica de auxiliar o aluno na compreensão de fenômenos e conceitos químicos. A necessidade de relacionar os fenômenos sobre os quais se referem os conceitos com o cotidiano justifica a experimentação como parte do contexto de aprendizagem, contribuindo com uma junção entre a teoria e a prática (Plicas, 2010).

A função das atividades experimentais é fazer com que a teoria se torne realidade. A mesma permite que os alunos manipulem objetos, construam ideias e negociem significados entre si e com o professor durante a aula. (Bueno et. al., 2007). A experimentação apresenta caráter indutivo e dedutivo. Durante o processo indutivo, o aluno controla variáveis descobrindo e 
redescobrindo relações funcionais entre essas variáveis. Enquanto no caráter dedutivo, o educando tem a oportunidade de testar o que é dito na teoria (Zimmermann, 1993).

Partindo desse pressuposto, o principal objetivo deste trabalho é investigar a influência e contribuições das atividades experimentais no processo de aprendizagem de conceitos relacionados ao estudo das Soluções Químicas.

Para isso, foi elaborada uma atividade denominada "Oficina de Cheiros", na qual os alunos da $2^{\circ}$ série do Ensino Médio de uma escola estadual de Colatina-ES, ao iniciarem o estudo sobre Soluções Químicas, com o apoio e orientação da professora de Química, desenvolveram a fabricação caseira de produtos higiênicos e/ou limpeza, que abordassem as misturas e diluição de solutos na presença de solventes.

\section{Metodologia}

Ao introduzir o conteúdo de Soluções Químicas para alunos da $2^{\circ}$ série do Ensino Médio, a professora regente propôs ao grupo de alunos a elaboração de uma "Oficina de Cheiros". Essa oficina consistiu na fabricação caseira de produtos higiênicos e/ou limpeza, que abordassem as misturas e diluição de solutos na presença de solventes.

No que se refere à estruturação metodológica dessa pesquisa, evidenciamos que à abordagem viabiliza uma atividade qualitativa, haja vista que o objetivo final não foi a representatividade numérica, e sim o aprofundamento e compreensão do objeto de estudo (Gerhardt \& Silveira, 2009). Quanto à natureza, a atividade foi experimental, pois objetivou "gerar conhecimentos para aplicação prática, dirigidos à solução de problemas específicos, envolvendo verdades e interesses locais" (Gerhardt \& Silveira, 2009, p. 35). Os dados foram analisados por meio do Método de Análise Observacional, o mesmo fundamenta-se em procedimentos de natureza sensorial, no qual o pesquisador é emergido ao mundo dos fenômenos empíricos, podendo assim captar com precisão os aspectos essenciais e acidentais desses fenômenos (Fachin, 2017).

Ressalta-se que a atividade não teve teor avaliativo, não sendo atribuído questionário e nem qualquer tipo de pontuação durante todo o processo de aplicação da experimentação.

A oficina teve duração de 5 aulas e ocorreu no período de 12/03/2019 a 26/03/2019. Ao desenvolver a mesma, foi solicitado o maior uso de substâncias simples e caseiras, que possam ser encontrados na própria residência. Os materiais de difícil compra, ou não encontrados na residência dos estudantes foram solicitados a professora e cedidos pela escola.

Dentre os materiais utilizados estão: óleo essencial, álcool de cereais, glicerina, vinagre, propilenoglicol, sabão de coco, borrifador, essências de baunilha (ou qualquer outra que tivesse em casa), pétalas de rosas, limão, garrafas pet, bicarbonato de sódio, álcool comum, amaciante e água.

Os alunos foram separados em 5 grupos contendo 7 participantes em cada. Cada grupo ficou responsável pela fabricação de um produto. Os produtos propostos para produção foram: amaciante, perfume, sabonete, detergente e aromatizador. A oficina foi dividida em 5 etapas:

\section{$1^{a}$ Etapa- Apresentação da oficina e aula de revisão}

Na primeira etapa do trabalho, foi apresentada a oficina a turma e a professora fez um levantamento de noções básicas sobre o conteúdo de Soluções, abrangendo a conceituação e exemplificação de solutos, solventes e diluição de soluções, no intuito de atualizar possíveis situações outrora esquecidas. Esse procedimento de análise dos conhecimentos prévios pressupõe, conforme Carvalho (2009), que o processo de ensino e aprendizagem se desenvolva partindo das experiências e vivências dos próprios alunos, ao valorizar e considerar conceitos pré-existentes na sua estrutura cognitiva. Em seguida os alunos foram divididos em 5 grupos de 7 alunos cada. Após a formação dos grupos, foi feito um sorteio para identificar qual produto cada grupo iria produzir. 


\section{$2^{\text {a }}$ Etapa- Pesquisa de como produzir os materiais propostos}

A segunda etapa ficou destinada a pesquisa do passo-a-passo da produção dos produtos e a elaboração da confecção do nome da marca e slogan. A seguir na Figura 1 segue imagem da marca criada pelo grupo responsável em produzir o aromatizador caseiro.

Figura 1: Imagem A (marca do aromatizador).

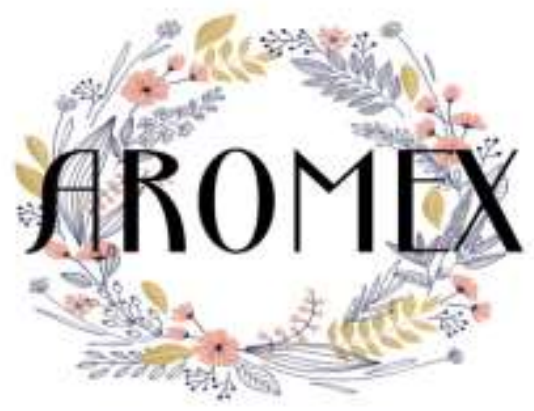

Fonte: Autores (2019).

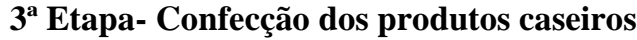

A terceira etapa destinou-se ao início da fabricação dos produtos, os alunos foram encaminhados ao laboratório da escola e durante os 10 primeiros minutos observaram a exemplificação da professora ao fazer uma diluição de solução simples com água e lavanda (essência que tinha em casa), fabricando assim um aromatizador de lavanda. Após o exemplo, os alunos foram direcionados cada um ao seu respectivo grupo e começaram a fabricar o produto proposto pelo professor orientador.

Na Figura 2 apresentam-se imagens da produção dos sabonetes caseiros.

Figura 2: Imagem B e C (produção dos sabonetes).
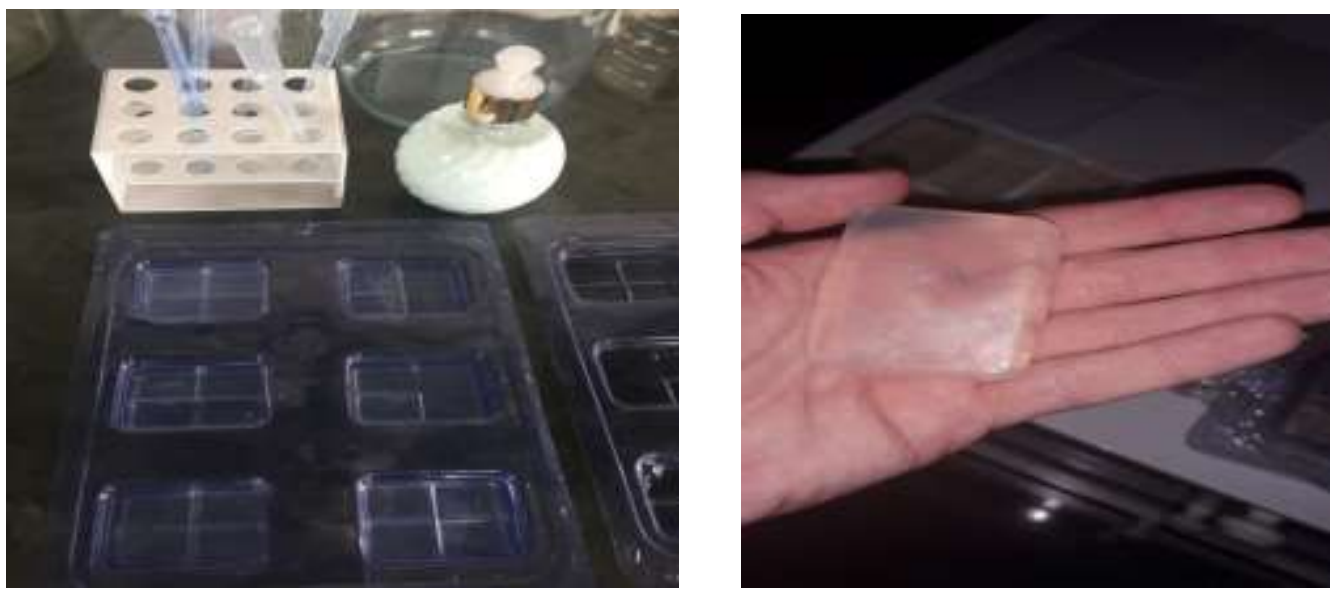

Fonte: Autores (2019).

\section{$4^{\mathrm{a}}$ Etapa- Continuação da fabricação dos produtos}

A quarta aula foi destinada a continuação da fabricação dos produtos. Os alunos foram orientados a terminarem a produção em casa, e durante o processo deveriam tirar fotos e enviá-las a professora, no intuito de realmente concluírem o projeto, fabricar mesmo e não comprar algo pronto para apenas apresentar e adquirir os pontos destinados a tal tarefa.

Na Figura 3 apresentam-se imagens da fabricação dos produtos sendo realizados em casa. 
Figura 3: Imagem D, E e F (produção do amaciante).
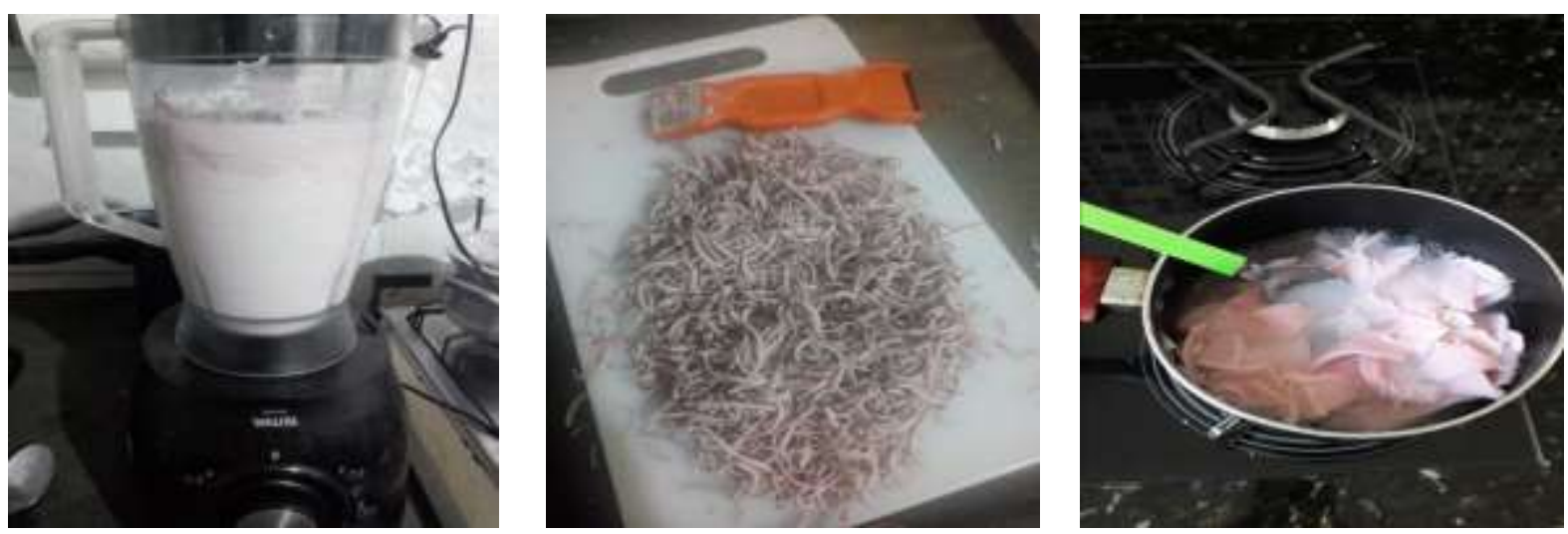

Fonte: Imagens cedidas pelos alunos (2019).

\section{$5^{\text {a }}$ Etapa- Apresentação dos produtos fabricados}

Os grupos apresentaram para toda turma o produto e como o mesmo foi produzido, especificando os procedimentos e materiais utilizados. A Figura 4 a seguir, apresenta imagens de alguns produtos em seu estado final.

Figura 4: Produto final.
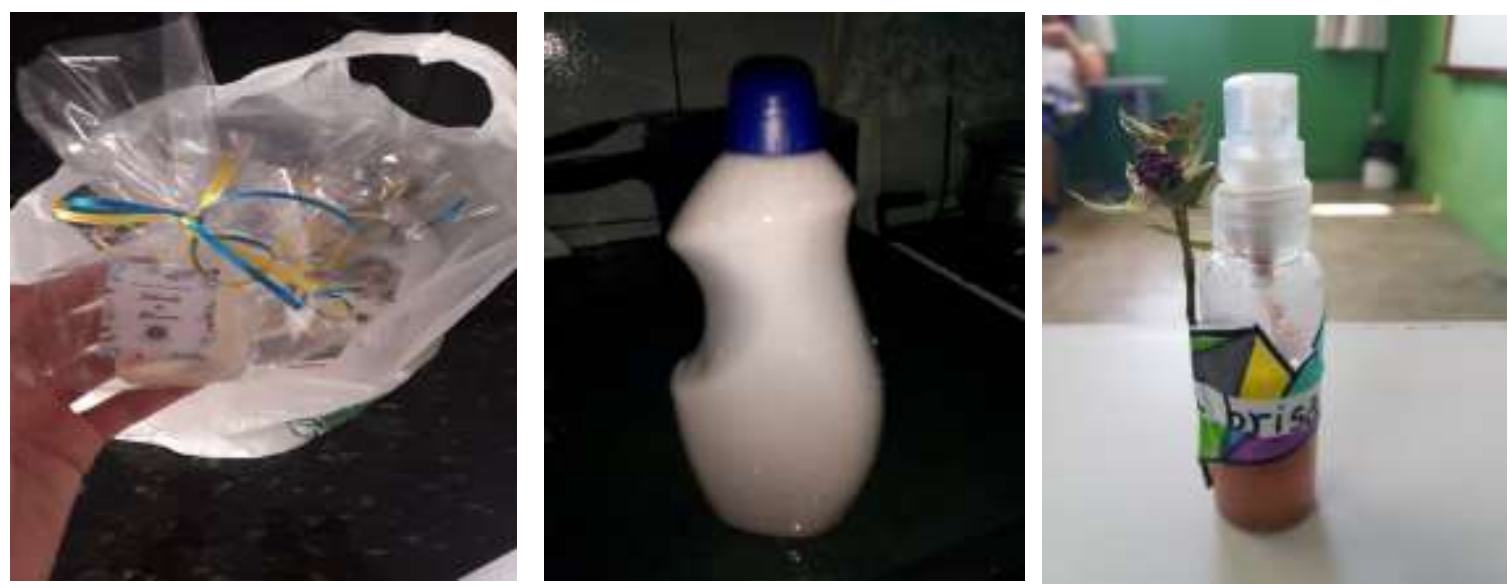

Fonte: Imagens cedidas pelos alunos (2019).

A experimentação com materiais alternativos permite que os estudantes manipulem objetos e negociem significados entre si, adequando seu uso ao ensino de Química. A abordagem do professor dos conteúdos escolares na prática de forma contextualizada possibilita a aprendizagem significativa por existir um referencial que permita aos alunos identificar e se identificar com as questões propostas, gerando, assim, a capacidade de compreender e intervir na realidade, numa perspectiva autônoma e desalienante (Masini \& Moreira, 1982).

\section{Contribuições das Atividades Experimentais ao Ensino de Química}

As aulas experimentais podem ser desenvolvidas com diferentes objetivos, em sua grande parte, abordam o caráter motivador e investigador do educando. Embora o contexto escolar entre a interação aluno-professor seja feita de forma 
tradicional, o trabalho em grupo é frequentemente apontado como uma estratégia de ensino que favorece a socialização dos alunos, influenciando os a ouvir e respeitar a opinião dos colegas (Galiazzi \& Gonçalves, 2004).

Nas aulas experimentais, especialmente as destinadas a desenvolver as atividades propostas em grupo, uma série de habilidades e competências são favorecidas: divisão de tarefas, responsabilidade individual e com o grupo, negociação de ideias e diretrizes para a solução dos problemas. Carvalho (2005) ressalta a necessidade de o professor ficar atento ao planejamento das atividades em grupo e a observação do andamento do trabalho durante as aulas. Não basta reunir grupos, é necessário ter embasamento para tal processo.

A atividade experimental em sala de aula permite a articulação de fenômenos e teorias, se conectando a vivência do cotidiano do educando ao pensamento perspicaz e reflexivo da ciência (Silva et al., 2011)

Quando o aluno é instigado a pesquisar e propor hipóteses para a solução de problemas ou a pensar e fornecer explicações para os fenômenos observados nos experimentos, automaticamente são estimulados a tomar decisões e expressar suas ideias para outras pessoas, oportunizando assim a formação social e capacidade de raciocínio (Galiazzi \& Gonçalves, 2004).

Hodson (1988) define a experimentação como um trabalho prático de aprendizagem, que permite o aluno construir novos entendimentos sobre o objeto estudado. Dentre as atividades experimentais citadas pelo autor, se encontram: experiências na bancada de laboratório, simulações em computador, demonstrações feitas pelo professor, vídeos ou filmes, estudo de caso, debates, seminários, teatro científico, confecções de modelos, jogos didáticos e aulas de campo.

Atividades experimentais objetivam a transposição dos limites do ensino formal e descritivo, que se direcionam a um cenário interativo e estimulador. O trabalho prático viabiliza o encontro do sujeito com as particularidades do objeto de aprendizagem, é a existência de algo novo (Souza, 2011).

Embora muitos professores reconheçam a importância da experimentação, poucos utilizam essa metodologia. O ensino de Química, em grande parte é limitado ao modelo tradicional de ensino, onde há apenas a transmissão e recepção do aprendizado (Moreira, 2012).

Luca (2001) considera que os professores não são preparados para trabalhar a Química em sala de aula. Alguns acabam se limitando a reproduzir um aprendizado tradicional, com pouquíssimos recursos pedagógicos. A prática pedagógica do professor revela suas concepções de ensino e de aprendizagem. Ao se deparar com professores que educam de forma tradicional, percebe-se que os mesmos foram formados de forma tradicional.

\section{O estudo das Soluções na Abordagem Significativa do Aprendizado}

Grande parte das substâncias encontradas no nosso cotidiano são misturas. Partes dessas misturas se integram ao conceito de homogeneidade, no qual duas ou mais substâncias ao se juntarem formam uma única fase. Essas misturas homogêneas recebem o nome de Soluções. Há diversos exemplos de Soluções ao nosso redor: produtos de limpeza, a água, o soro fisiológico, correntes de ouro (Russel, 2008).

Marcondes (2008) cita que as Soluções podem ser gases, líquidos ou sólidos. O mesmo esclarece que em uma solução há a presença de solvente e soluto. Sendo que o mais comum é ter o soluto dissolvido por um solvente. Tais soluções podem ser preparadas dissolvendo- se um sólido em um líquido (sal em água), um líquido em outro líquido (etanol em água), ou gás em um líquido (bebida gaseificada contendo dióxido de carbono dissolvido em água).

Ao abordar o conteúdo de Soluções espera- se que o educando desenvolva competências necessárias para utilização das linguísticas científicas, com capacidade de reconhecer os fenômenos e as transformações químicas.

No contexto escolar, o aluno é centro do processo educativo. Todo aluno é um ser pensante, original e portador de perfil intelectual único. Essas compreensões são fundamentadas na teoria cognitiva que reconhece a existência de diferentes 
tipos de mentes. Cada sujeito constrói um espaço mental próprio, povoado de representações singulares da realidade (Moraes, 2004).

Partindo do pressuposto que o foco da escola é o aluno, o principal eixo da escolarização é a aprendizagem. Deve- se ensinar pensando em como o aluno aprende, e esse processo de construção do saber está ligado diretamente as teorias de aprendizagem. As teorias de aprendizagem estão fixadas em valores filosóficos, que procuram explicar como o indivíduo aprende. Ao olhar os diversos aportes teóricos que integram o processo de aprendizagem, devemos levar em conta o conhecimento que o educando já tenha se apropriado, o conhecimento prévio adquirido nos anos anteriores e no seu meio cultural. Diante disso, o professor passa a ter o papel de mediador das informações já adquiridas pelo aluno ao longo do ensino médio e começa a preparação para a introdução de um novo e fundamental conceito na vida escolar.

A introdução desse novo conceito está relacionada à Teoria da Aprendizagem Significativa, proposta por David Paul Ausubel. A qual afirma que é a partindo de conteúdos que indivíduos já possuem na sua estrutura cognitiva, que aprendizagem pode ocorrer. É através desses conteúdos prévios que novos conteúdos deverão ser introduzidos, modificando e criando novas significações àquelas pré-existentes (Ausubel, Novak \& Hanesian, 1983).

Aprendizagem Significativa é, portanto, um processo por meio do qual uma nova informação é acoplada a uma estrutura cognitiva particular e específica, prévia, conhecida como subsunçor. Ausubel diz: "o fator mais importante que influi na aprendizagem é aquilo que o aluno já sabe. Isto deve ser averiguado e o ensino deve depender desses dados” (Ausubel, Novak \& Hanesian, 1983).

Segundo Ausubel (1983), é indispensável para que haja uma aprendizagem significativa, que os alunos se predisponham a aprender significativamente, surgindo então à necessidade de despertar no aluno o desejo, à vontade, o anseio pela aprendizagem. Como despertar no educando a predisposição a uma aprendizagem?

De acordo com Benite (2006), as diferentes tecnologias para o Ensino de Química, proporcionam além de pesquisas, algumas simulações que podem despertar grande interesse científico ao educando, proporcionando ao mesmo a chance de manipular ou até mesmo a confecção de materiais de uso científico.

Sobre esse assunto, Penin (2001, p. 37) afirma:

O acesso ao saber não mais seguirá apenas a ordem hierárquica e progressiva como geralmente é disposta na programação de uma disciplina ao longo das séries escolares. A tecnologia disponível, sobretudo através da internet, MS também em programas já existentes, como os de vídeo, possibilita diferentes formas de acesso ao saber [...]. Essa novas oportunidades de aprendizagem, se disponíveis aos alunos, provocam a necessidade de uma mudança profunda didática utilizada pelos professores. Mais do que seguir um programa, eles precisam relacionar e dar sentido a essa trama a que os alunos estão submetidos.

O papel do professor neste tipo de atividade é distinto. Sua função é essencialmente auxiliar os alunos na busca das explicações causais, negociar estratégias para resoluções de problemas, questionar as ideias dos alunos, incentivar a criatividade epistêmica em todas as etapas da atividade e mediar o grupo e as tarefas, intervindo nos momentos em que há indecisão, falta de clareza ou consenso.

\section{Resultados e Discussões}

O sabonete é uma evolução do sabão utilizando produtos mais nobres na sua fabricação, tais como: glicerina, extrato glicólico, corantes e aromatizantes, utilizando a mesma química empregada na produção de sabão. O mesmo é utilizado para evitar a presença de impurezas de odor desagradável, mais frequentes no sabão em barra, antes de adicionar as essências escolhida para perfumar adequadamente o produto (Perruzo \& Canto, 2010).

Para compreender o processo de fabricação do sabonete, deve-se seguir os mesmos conceitos teóricos utilizados para 
a fabricação do sabão. O sabão é obtido de gorduras (de boi, porco, etc.) ou de óleos (de algodão, girassol, etc.). Durante a reação química ocorre a hidrólise de glicerídeos, denominada de reação de saponificação utilizando um éster proveniente de um ácido graxo, resultando em um sal que recebe o nome de sabão (Feltre, 2004).

Na Figura 5 apresenta-se o mecanismo químico durante a reação de saponificação.

Figura 5: mecanismo da reação de saponificação.
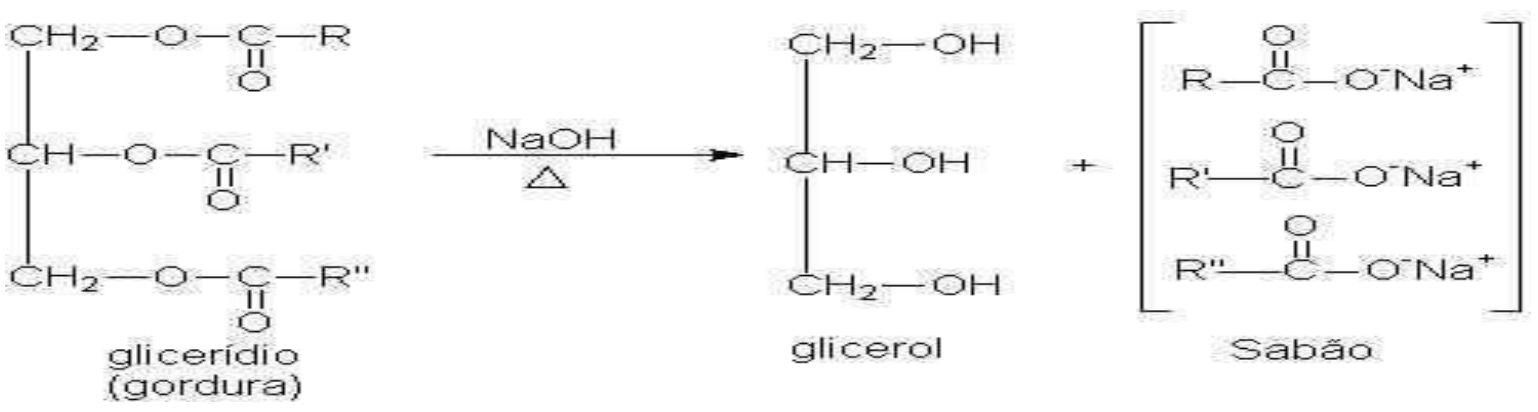

glicerol

Sabâa

Fonte: Feltre (2004, p.346)

Os sabões são formados por moléculas que possuem uma cadeia carbônica extensa e apolar, portanto, solúvel em gorduras, contendo em sua extremidade o grupo carboxilato (-COO- ), que é polar e, portanto, solúvel em água. Devido a isso o sabão remove a gordura porque sua parte apolar atrai a gordura, possibilitando a formação e a solubilização de gotículas de gordura na água (Feltre, 2004).

Para a produção dos perfumes artesanais os principais conceitos químicos utilizados foram: Destilação, Dissolução e Misturas.

De acordo com Jesus (2013), os perfumes são compostos de mistura de fragrâncias que podem ser divididas em grupos, conforme a volatilidade das substâncias componentes: cítrica, lavanda, ervas, aldeídica, verde, frutas, floral, especiarias, madeira, couro, animal, almíscar, incenso, baunilha.

De acordo com Ashcar (2007, p.1) os perfumes também eram aplicados no corpo através de óleos perfumados com finalidade terapêutica e também utilizados como cosméticos para o embelezamento do corpo.

As essências podem ser de origem natural ou sintética. As de origem natural são geralmente extraídas de plantas, flores, raízes ou animais, enquanto as sintéticas tentam reproduzir no laboratório os aromas naturais (Guimarães et al, 2000). Os métodos mais comuns de extração de óleos essenciais são: enfloração, destilação por arraste a vapor e extração com solvente orgânico (Serafini et al., 2007).

De acordo com Oliveira e José (2007), no processo de enfloração é utilizada uma espécie de solvente para segurar o óleo. Esse método é utilizado para extração de óleos essenciais de plantas delicadas e com baixo teor de óleos essenciais, e que não podem ser destiladas a vapor, porque pode provocar perdas quase completas de seus compostos aromáticos.

A extração por destilação de arraste a vapor é realizada colocando o material vegetal sobre uma placa com orifícios que possibilitam a passagem do vapor introduzido no sistema de forma indireta. O vapor, ao passar pelo material vegetal, destrói as glândulas e arrasta o óleo essencial contido nas mesmas. A mistura óleo e água é condensada e posteriormente as fases são separadas. (Pinheiro et al 2014).

Já a extração com solvente orgânico é realizada a temperatura ambiente usando solventes orgânicos, principalmente os apolares (hexano, éter, éter de petróleo ou diclorometano), no qual extraem além do óleo essencial, os componentes 
responsáveis pela pungência, pigmentos e componentes indesejados (Grossman, 2006).

A realização desse projeto resultou na participação da escola na "Feira de Ciências do Norte Capixaba- FECINC", realizada pelo Instituto Federal do Espírito Santo (IFES) campus São Mateus nos dias 30/05/2019 e 31/05/2019, e a obtenção do prêmio de "Apresentação Destaque" do evento.

No intuito de incentivar a iniciação científica dos educandos, a professora de Química ao saber da abertura de inscrições de projetos que promovessem a alfabetização científica a estudantes de ensino médio na Feira de Ciências do Norte Capixaba, decidiu realizar a inscrição da escola na Feira, no intuito de desenvolver o "gosto" pela pesquisa científica nos alunos.

Cada projeto inscrito deveria conter no máximo 3 (três) alunos, seguidos de um professor orientador. O projeto desenvolvido em sala de aula, envolveu toda a turma da $2^{\circ}$ série do Ensino médio da escola. Diante disso, para fazer a escolha dos 3 alunos representantes entre os 35 alunos da sala, caso o protótipo fosse aceito, então a professora em parceria com o setor pedagógico analisou os alunos de acordo com os seguintes critérios:

- $\quad$ Os alunos que obtiveram melhor desempenho nas atividades propostas;

- $\quad$ Os alunos com maior comprometimento em cumprir os prazos estabelecidos;

- A maior desenvoltura e melhor comportamento durantes as apresentações.

Durante o processo, foi justificada a turma os critérios de escolha e os motivos de apenas três alunos serem escolhidos para representação da escola. Após a escolha dos alunos representantes, foi elaborado um pré-projeto apara participação na Feira e enviado conforme o cronograma estabelecido pelo IFES.

Os alunos tiveram o projeto "Oficina de Cheiros" aprovado para participação na FECINC. O evento contou com a participação de 18 escolas de diferentes municípios do Espírito Santo, sendo nossa escola a única a representar o município de Colatina.

Vale ressaltar, que a comunidade escolar foi de total apoio antes e durante a participação dos alunos na Feira, disponibilizando recursos para confecção de materiais, alimentação, estádia e transporte dos alunos durante os dois dias de realização do evento. A participação dos alunos na Feira de Ciências promovida pelo IFES pode proporcionar aos mesmos, momentos de socialização e aprendizagem com outros grupos de estudantes presentes no projeto. Contribuiu com o desenvolvimento do desejo de realizar pesquisas e projetos com teor científico, além de abranger a capacidade intelectual e social do educando.

Um dos alunos participantes do evento destaca a importância de vivenciar atividades desse nível acadêmico para o desenvolvimento cognitivo e para despertar um maior interesse pela disciplina.

A 1- "Participar da Feira foi uma experiência única e marcante de aprendizado. O momento nos levou a se sentir ainda mais motivados pela Química e a dedicação aos estudos”.

A Figura 6 apresenta imagens dos alunos durante a participação na Feira de Ciências do Norte Capixaba- FECINC. 
Figura 6: Imagem dos alunos durante a participação na Feira.

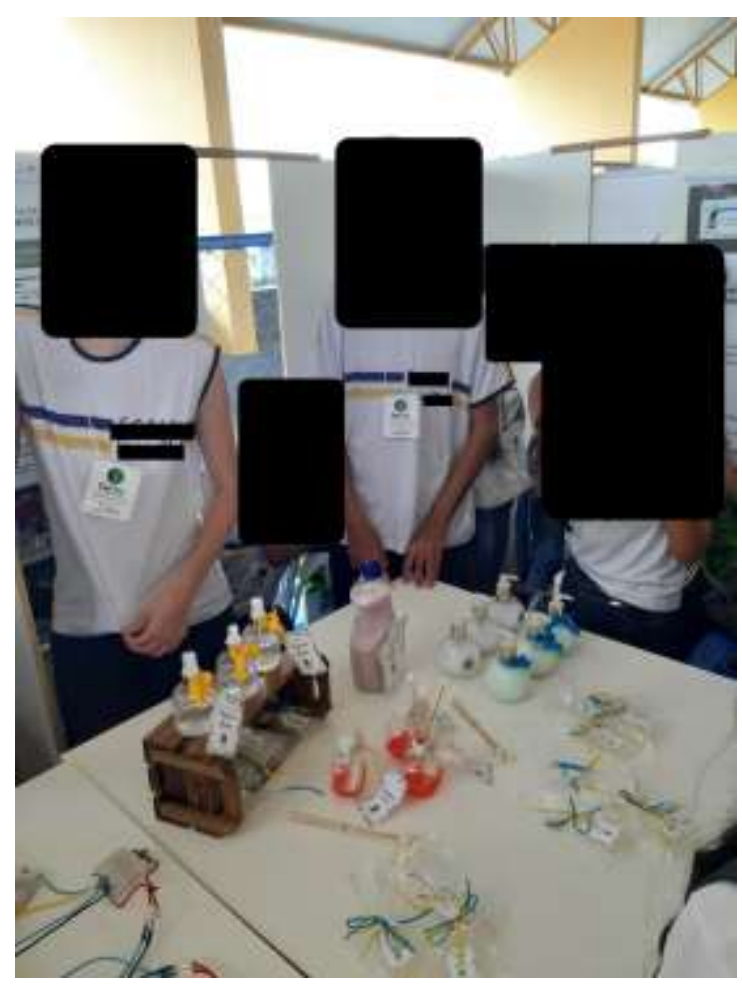

Fonte: Autores (2019).

A participação da escola na FECINC trouxe grande repercussão na comunidade escolar e serviu como incentivo para os demais estudantes da escola. Ao verem a oportunidade de aprendizagem e socialização que os participantes tiveram ao se apresentarem em outra cidade e em um Instituto Federal, os alunos do $2^{\circ}$ ano passaram a se empenhar mais nas atividades e projetos desenvolvidos na disciplina de Química, a fim de conseguirem uma nova participação na próxima Feira de Ciências.

Antes da realização do projeto "Oficina de Cheiros", dos 10 pontos possíveis (até então na matéria de Química) aplicados pela professora, 12 alunos constavam nota na média, 06 alunos constavam nota acima da média e 17 alunos constavam nota abaixo da média. A Tabela 1 explicita a pontuação dos alunos anterior a realização da Oficina.

Tabela 1: Pontuação dos alunos antes da realização da oficina de cheiros.

\begin{tabular}{lc}
\hline ETAPA & QUANTIDADE \\
\hline Na média & 12 \\
Acima da média & 6 \\
Abaixo da média & 17 \\
Total de alunos: & 35 \\
\hline
\end{tabular}

Fonte: Autores (2019).

Após o projeto e ao final do trimestre, a disciplina de Química apresentou 5 alunos com nota na média, 25 alunos obtiveram nota acima da média e 5 alunos apresentaram nota abaixo da média. A Tabela 2 apresenta as pontuações após a realização da Oficina. 
Tabela 2: Pontuação dos alunos após a realização da oficina de cheiros.

\begin{tabular}{lc}
\hline ETAPA & QUANTIDADE \\
\hline Na média & 5 \\
Acima da média & 25 \\
Abaixo da média & 5 \\
Total de alunos: & 35 \\
\hline
\end{tabular}

Fonte: Autores (2019).

Percebe-se que após a aplicação da oficina, os educandos motivados pela atividade, alcançaram um rendimento melhor dentro da disciplina. A mesma gerou mudanças dentro do contexto outrora abordado, favorecendo a ampliação de possibilidades e estratégias pedagógicas.

Partindo da necessidade de mudanças entre os paradigmas e a apropriação da interdisciplinaridade e transdisciplinaridade dos conceitos, reconheço a relevância social deste trabalho, pois além de contribuir para uma aprendizagem significativa, o mesmo pôde arremeter ao aluno a necessidade de cuidados com o meio ambiente. Ao desenvolver a "Oficina de Cheiros", os educandos se depararam com atividades que contribuíram para a reciclagem de materiais que tinham em casa e que seriam descartados. A atividade proposta pelo professor, além de consistir na fabricação de produtos caseiros de higiene/limpeza, também teve como requisito principal a criação de uma marca e slogan para o produto fabricado. Com isso, a professora tinha como objetivo incentivar o empreendedorismo e desenvolver o lado criativo dos educandos envolvidos.

Apesar de estar localizada em um bairro considerado nobre, o público predominante atendido pela escola reside em bairros periféricos, circunvizinhos da escola, bairros esses com baixa infraestrutura urbana e situação de carência econômica. Partindo dessa realidade crítica, entendo como contribuição desse tema à comunidade familiar, a possibilidade de ampliação do projeto as respectivas famílias dos alunos com a intenção de ensina-los a fabricação caseira de produtos que possam vir a contribuir futuramente com uma renda extra, ou até mesmo despertar a habilidade para fabricação de produtos artesanais.

\section{Considerações Finais}

Com o desenvolver dos trabalhos, contemplando a experimentação, foi possível identificar que realmente, a prática unida à teoria dentro do estudo da Química pode auxiliar o desenvolvimento do processo de ensino aprendizagem. As atividades experimentais acabam por contribuir com o processo de ensino, pois permite que o próprio aluno estabeleça relações dos conteúdos teóricos vistos em sala de aula com sua vida cotidiana. O educando, quando motivado pelo professor, torna-se um investigador do próprio conhecimento, e passa a ser o protagonista do seu processo de ensino a aprendizagem, tornando o ensino potencialmente significativo.

O uso da experimentação como recurso metodológico, permitiu maior envolvimento e motivação por parte do educando ao realizar as atividades da disciplina. Porém, não pode afirmar, de fato, que houve a aprendizagem significativa de todos os conceitos abordados, por parte de todos os alunos envolvidos, entretanto, o objetivo da pesquisa foi atingido, o de gerar uma influência e motivação maior pelo aprendizado através das atividades experimentais.

O professor ao mudar a prática pedagógica contribuiu com a mudança de comportamento dos alunos participantes da atividade, fazendo com que os mesmos se envolvessem mais com as aulas de forma participativa e interativa. 
Conclui-se, portanto, que a experimentação no ensino é de fundamental importância no contexto escolar, despertando um forte interesse entre os educandos, mostrando o papel da Química no cotidiano e sendo umas das ferramentas fundamentais para o processo de ensino-aprendizagem.

\section{Referências}

Ausubel, D. P, Novak, J. D., \& Hanesian, H. (1983). Psicología Educativa: un punto de vista cognoscitivo. Trillas.

Ashar, R. (2007). “A história do perfume da antiguidade até 1900”. Com Ciência n. 91, p. 1.

Benite, C. R. M. (2006). Avaliação de Tecnologias Educacionais no Ensino de Química em Nível Médio. Monografia (Especialização no Ensino de Ciências). UFRJ.

Bueno, L, Moreia, K. C, Soares, M, Wiezzel, A. C. D, Teixeira, M F S \& Dantas, D. J. (2007). O ensino de química por meio de atividades experimentais: a realidade do ensino nas escolas. In: Silvania, L. N.; José, M. de L. (Org.). Livro Eletrônico do Segundo Encontro do Núcleo de Ensino de Presidente Prudente São Paulo: Unesp.

Fachin, O. (2017). Fundamentos da Metodologia Científica: noções básicas em pesquisa científica. (6a ed.), Saraiva.

Feltre, R. (2004). Química orgânica. Moderna, 3, 346-347.

Fiorucci, A. R, Soares, M. H. F. B \& Cavalheiro, E. T. G. (2002). Ácidos Orgânicos: dos Primórdios da Química Experimental à Sua Presença em Nosso Cotidiano. Química Nova na Escola, n. 15.

Galiazzi, M. C \& Gonçalves, F. P. (2004). A natureza pedagógica da experimentação: uma pesquisa na licenciatura em química. Química Nova, 27(2), 326331.

Gerhardt, T. E \& Silveira, D. T. (organizadores). (2009). Métodos de Pesquisa. Coordenado pela Universidade Aberta do Brasil - UAB/UFRGS e SEAD/UFRGS. Editora da UFRGS.

Guimarães, C. C. (2009) Experimentação no ensino de química: caminhos e descaminhos rumo à aprendizagem significativa. Química Nova na Escola; 31(3).

Guimarães, P. I. C, Oliveira, R. E. C \& Gomes R. A. (2000). Extraindo óleos essenciais de plantas. Revista Química Nova na Escola. $45-46$.

Grossman, M. (2006). "Education and Nonmarket Outcomes," Handbook of the Economics of Education, Elsevier.

Jesus, H. C. (2013). Show de química: Aprendendo química de forma lúdica e experimental. GSA, (2a ed.).

Masini, E. A. F. \& Moreira, M. A. (2008). Aprendizagem significativa: condições para ocorrência e lacunas que levam a comprometimentos. Vetor Editora.

Moraes, R., Ramos, M. G., \& Galiazzi, M. C. (2012). Aprender química: promovendo excursões em discursos da química. In: Zanon, L. B.; Maldaner, O. A. (Org.). Fundamentos e propostas de ensino de química para a educação básica no Brasil. Ijuí: Unijuí.

Moreira, M. A. (2012). O Que é Afinal Aprendizagem Significativa? Qurriculum, La Laguna, 25, 29-56.

Oliveira, S. M. M. \& Jose, V. L. A. (2007). Processos de extração de óleos essenciais. Instituto de Tecnologia do Pará.

Penin, S.T.S. (2001). Didática e Cultura: O Ensino Comprometido com o Social e a Contemporaneidade. In: Castro, A. D.; Carvalho, A. M. P. (org).Ensinar a Ensinar - Didática para a Escola Fundamental e Média. São Paulo: Pioneira/Thomson.

Peruzzo, F. M \& Canto, E. L. (2010). Química orgânica, Moderna, 3, 279.

Pinheiro, J. A. Et al. (2014). Atividade antileishmanial de alguns óleos voláteis. Tópicos Especiais de doença animal III, CAUFE.

Plicas, L. M. A. (2010). O uso de práticas experimentais em Química como contribuição na formação continuada de professores de Química. Instituto de Biociências, letras e Ciências Exatas - UNESP, São José do Rio Preto.

Serafini, L. A.; Santos, A. C. A, Touguinha, L. A.; Agostini, G \& Dalfovo, V. (2002). Extrações e aplicações de óleos essenciais de plantas aromáticas e medicinais. Caxias do Sul: EDUCS.

Silva, R. R., Machado, P. F. L \& Tunes, E. (2010). Experimentar sem medo de errar. In: Santos, W. L. P.; Maldaner, O. A. (Org.). Ensino de Química em Foco. Ijuí: Unijuí.

Sousa, P. A. A \& Sousa, H. R. (2011). Estimulando o ensino de química através de ilustrações. In: Congresso Brasileiro de Química, 55., 2011, Goiânia. Anais. Goiânia, CBQ.

Zimmermann, A. (1993). O ensino de química no $2^{\circ}$ grau numa perspectiva interdisciplinar. Palotina. SEED. 